\title{
Characterization of the glycans involved in sea urchin Paracentrotus lividus reversible adhesion
}

\author{
Mariana Simão ${ }^{1} \cdot$ Mariana Moço $^{1} \cdot$ Luís Marques $^{2,3} \cdot$ Romana Santos $^{1}$ (D)
}

Received: 1 April 2020 / Accepted: 14 May 2020 / Published online: 5 August 2020

(c) The Author(s) 2020

\begin{abstract}
Sea urchins have hundreds of specialized adhesive organs, the tube feet, which play a key role in locomotion, substrate attachment and food capture. Tube feet are composed by two functional units: a proximal cylindrical stem that is mobile and flexible, attached to a distal flattened disc that produces adhesive secretions. Oral tube feet discs possess a specialized duo-glandular epidermis that produces adhesive and de-adhesive secretions, enabling strong but reversible adhesion to the substrate. Due to the growing interest in biomimetic adhesives, several studies have been carried out to characterize sea urchin adhesives, and up to date, it has been shown that it is composed by proteins and glycans. The protein fraction has been the subject of several studies, that pin-pointed several adhesion-related candidates. Contrastingly, little is known about the glycans that compose sea urchin adhesives. This study aims at contributing to this topic by focusing on the characterization of the glycosidic fraction of the adhesive secreted by the sea urchin Paracentrotus lividus (Lamarck, 1816), using a battery of 22 lectins, applied to 3 complementary techniques. Our results show that five lectins label exclusively the disc adhesive epidermis and simultaneously the secreted adhesive, being, therefore, most likely relevant for sea urchin adhesion. In addition, it was possible to determine that the glycosidic fraction of the adhesive is composed by a high molecular weight glycoprotein containing $\mathrm{N}$-acetylglucosamine oligomers.
\end{abstract}

Responsible Editor: M. Byrne.

Reviewed by undisclosed experts.

Electronic supplementary material The online version of this article (https://doi.org/10.1007/s00227-020-03707-9) contains supplementary material, which is available to authorized users.

Romana Santos

rlasantos@fc.ul.pt

1 Centro de Ciências do Mar e do Ambiente (MARE), Departamento de Biologia Animal, Faculdade de Ciências, Universidade de Lisboa, 1749-016 Lisboa, Portugal

2 Centro de Ecologia, Evolução e Alterações Ambientais (cE3c), Departamento de Biologia Animal, Faculdade de Ciências, Universidade de Lisboa, 1749-016 Lisboa, Portugal

3 Instituto de Biossistemas e Ciências Integrativas (BioISI), Departamento de Biologia Animal, Faculdade de Ciências, Universidade de Lisboa, 1749-016 Lisboa, Portugal

\section{Introduction}

Like other echinoderms, sea urchins have an ambulacral system made up of hundreds of specialized adhesive organs, called tube feet (Fig. 1a), used for substrate attachment, locomotion and food capture (Flammang et al. 2016).

Tube feet are composed by a stem and a disc (Fig. 1b). The stem is attached to the animal's test, being flexible and mobile. The disc is at the distal end of the stem, has a flat shape and viscoelastic properties ideal for contact and adhesion to the substrate (Flammang 1996; Santos et al. 2005). Histologically, tube feet are composed of an internal myomesothelium, connective tissue, a nervous plexus and an outer epidermis lined by a cuticle (Santos and Flammang 2006). The central area of the disc epidermis has adhesive properties due to the presence of two types of secretory cells that produce adhesive and de-adhesive secretions. This provides sea urchins with strong but reversible adhesion. After detachment, the adhesive secretion usually remains firmly attached to the substrate as a circular adhesive footprint (Fig. 1c) (Santos and Flammang 2006).

The secreted adhesive has been characterized in terms of structural and biochemical composition. It consists of 

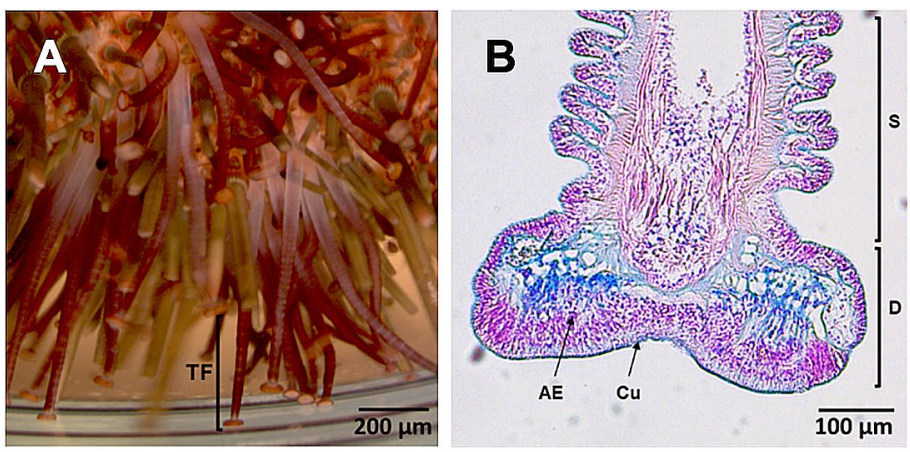

C

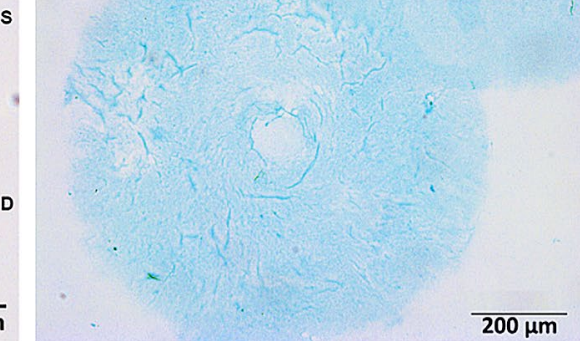

Fig. 1 Sea urchin Paracentrotus lividus adhesive organs and footprints. Oral tube feet attached to the wall of a glass aquarium (a). Longitudinally sectioned tube foot (b) and adhesive footprints (c) stained with Alcian Blue. $A E$ adhesive epidermis, $C u$ cuticle, $D$ disc, $S$ stem, $T F$ tube foot

$\mathrm{N}$-acetylgalactosamine residues, and terminal $\mathrm{N}$-acetylgalactosamine linked to galactose residues. It also contains large glycoconjugates with sialic acids (Hennebert et al. 2011). This study demonstrated the usefulness of lectins to characterize the glycans present in marine adhesives, as they have been in the past to characterize the glycans present in the hyaline layer of sea star larvae (Cerra 1999; Reimer and Crawford 1990). However, Hennebert et al. (2011) also points out for the fact that glycan conformation, and thus the exposed epitopes of the glycoconjugates, differ according with the employed technique.

Therefore, in the present study, we aim at further characterizing the glycans involved in sea urchin reversible adhesion, by means of a battery of 22 lectins and 3 complementary techniques, to specifically recognize various glycan motifs, distinguish if they are covalently linked to proteins or not, and localize them in the tube foot adhesive epidermis and in the adhesive secretion.

\section{Materials and methods}

\section{Collection and maintenance of sea urchins}

Adult individuals of the sea urchin Paracentrotus lividus (Lamarck 1816) were collected intertidally along the western coast of Portugal (Ericeira; $38.9756^{\circ} \mathrm{N}, 9.4203^{\circ} \mathrm{W}$ ) and kept in re-circulating aquariums at $16^{\circ} \mathrm{C}$ and $33 \mathrm{PSU}$.

\section{Collection of sea urchin tube feet and adhesive footprints}

Sea urchins were placed upside down in containers filled with artificial seawater and their tube feet sectioned by the base of the stem close to the test. Tube feet for histochemistry were immediately fixed in $2 \%$ paraformaldehyde in $0.12 \mathrm{M}$ phosphate buffer with $0.12 \mathrm{mM} \mathrm{CaCl}_{2}$ (PBS) and 
$4 \%$ sucrose, at $4{ }^{\circ} \mathrm{C}$. Tube feet for biochemistry analysis were further dissected to separate discs (adhesive part) from stems (non-adhesive) and then stored at $-20^{\circ} \mathrm{C}$ until further use.

To collect adhesive footprints, clean microscope glass slides were presented to tube feet to induce attachment. Once obtained, glass slides were abundantly washed with distilled water and immediately processed for histochemistry assays.

\section{Protein extraction and quantification}

Proteins from disc and stem samples were extracted with RIPA buffer (150 mM NaCl, 1.0\% Triton X-100, 0.5\% sodium deoxycholate, $0.1 \%$ SDS, $50 \mathrm{mM}$ Tris, $\mathrm{pH}$ 8.0) supplemented with a protease and phosphatase inhibitor cocktail at a dilution of 1:10,000 (Sigma). In addition to chemical lysis, mechanical lysis was also carried out. For this, eight metal spheres with $2 \mathrm{~mm}$ in diameter (Retsch, Germany) were added to each tube containing the samples and the buffer, and these were placed in a ball mill (Retsch, Germany) for $10 \mathrm{~min}$ in a previously refrigerated teflon tube holder (Retsch, Germany). Afterwards, the spheres were removed, and samples centrifuged at $14,000 \mathrm{rpm}$ for $10 \mathrm{~min}$ at $4{ }^{\circ} \mathrm{C}$. The supernatant was collected and kept at $-20{ }^{\circ} \mathrm{C}$ until further use.

The total protein concentration in the samples was determined using the Bradford colorimetric microplate assay (Bio-Rad, USA) and absorbances were obtained at wavelength of $595 \mathrm{~nm}$ using a spectrophotometer (Bio Tek Synergy HT, USA).

\section{Lectin assays}

Lectins are proteins or glycoproteins of non-immune origin that are able to bind glycans without chemical modification (Leathem and Atkins 1983). Twenty-two biotinylated lectins, purchased from Vector Laboratories (Burlingame, USA), were used. Their full names, natural sources, and glycan specificities are listed in Table 1. The presence of specific glycan residues in sea urchin tube foot sections, adhesive material, and tube foot disc and stem protein extracts was tested by lectin histochemistry, enzyme-linked lectin assay and lectin blotting.

\section{Lectin histochemistry}

Tube feet were fixed, embedded and prepared for cryosectioning according to Bajanca et al. 2004. Briefly, tube feet were fixed in $2 \%$ paraformaldehyde in $0.12 \mathrm{M}$ phosphate buffer with $0.12 \mathrm{mM} \mathrm{CaCl}_{2}$ (PBS) and $4 \%$ sucrose, at $4{ }^{\circ} \mathrm{C}$ for $4 \mathrm{~h}$. Then, they were decalcified with a 1:1 solution of $2 \%$ ascorbic acid and $0.3 \mathrm{M} \mathrm{NaCl}$ for $24 \mathrm{~h}$ at RT with constant rotation. Subsequently, tube feet were washed in PBS and then changed to PBS with $4 \%$ sucrose for $6 \mathrm{~h}$ at
$4{ }^{\circ} \mathrm{C}$. After PBS washes, tube feet were incubated in PBS with $15 \%$ sucrose at $4{ }^{\circ} \mathrm{C}$, overnight, and then changed to PBS with $15 \%$ sucrose and $7.5 \%$ gelatine for $1 \mathrm{~h}$ at $37{ }^{\circ} \mathrm{C}$. Then, tube feet were immediately frozen in dry ice-chilled isopentane and stored at $-80{ }^{\circ} \mathrm{C}$ until sectioned. Approximately, $15-\mu \mathrm{m}$-thick serial sections were collected on Super Frost slides (Thermo Fisher Scientific, USA), permeabilized and blocked in Tris-buffered saline, $\mathrm{pH}$ 8.0, containing $0.05 \%(\mathrm{v} / \mathrm{v})$ Tween 20 and $3 \%(\mathrm{w} / \mathrm{v})$ bovine serum albumin (TBS-T-BSA).

A few sections were stained with Alcian Blue pH 2.5 staining kit (Vector Laboratories, USA) and observed with a Leica DM 2500 LED (Leica Microsystems). Other sections were subjected to an indirect lectin histochemical staining method according to the following protocol. Lectins were prepared in TBS-T-BSA supplemented with ions ( $1 \mathrm{mM} \mathrm{CaCl}_{2}, 1 \mathrm{mM} \mathrm{MnCl} \mathrm{mM}_{2}, 1 \mathrm{mgCl} \mathrm{Mg}_{2}, 1 \mathrm{mM} \mathrm{ZnCl}_{2}$ ) (see Table $\mathrm{S} 1$ for concentrations), incubations were performed for $2 \mathrm{~h}$ at RT, followed by three washes in TBST. Afterwards, sections were incubated for $1 \mathrm{~h}$ at RT in Alexa Fluor 488-conjugated streptavidin (Invitrogen, USA) in TBS-T-BSA (see Table S1 for dilutions), followed by TBS-T washes. Finally, slides were incubated with DAPI (4', 6-diamidine-2-phenylindole; Invitrogen, USA) for $1 \mathrm{~min}$ at RT in the dark, washed in PBS and mounted in Vectashield, (Vector Laboratories, USA). Control reactions were performed by substituting the lectins with TBS-T-BSA. Sections were observed using an Olympus BX60 widefield fluorescent microscope, equipped with a $10 \times 0.4 \mathrm{NA}$ lens and appropriate filter cubes, coupled to a Hamamatsu Orca R2 monochrome camera and running Micro-Manager 2.0 gamma (Edelstein et al. 2014); and on a Leica SPE confocal microscope equipped with $10 \times / 0.3 \mathrm{NA}, 20 \times / 0.7 \mathrm{NA}$, $63 \mathrm{x} / 1$.4NAlenses, appropriate laser lines, and running LAS $\mathrm{X}$. All confocal imaging done at Airy $=0.8$ and respecting the Nyquist sampling criterium in xyz. Image visualization and basic histogram manipulation for clarity were done using Fiji/ImageJ (Schindelin et al., 2012).

The same procedure was applied on freshly collected footprints. Some of these footprints were stained with Alcian Blue pH 2.5 (Vector Laboratories, USA); the others were labelled with the biotinylated lectins using the same protocol as for tube foot sections (see Table S1 for concentrations and dilutions).

\section{Enzyme-linked lectin assay}

Wells of a 96-well microplate (Brand) were coated with $1 \mu \mathrm{g}$ of protein per well at $4{ }^{\circ} \mathrm{C}$ and blocked with $0.5 \%$ polyvinyl alcohol in PBS for $2 \mathrm{~h}$ at RT. Polyvinyl alcohol was used as a blocking solution, since it prevents nonspecific interactions with the plate surface, and does not interfere with the ability of lectins to interact with immobilized glycoproteins 
Table 1 Biotinylated lectins grouped according to their binding specificity (according to Debray et al. 1986, EY Labs—https://eylabs.com/ and Vector Laboratories-https://www.vectorlabs.com/)

\begin{tabular}{|c|c|c|c|}
\hline Lectin name & Acronym & Detected glycan & \\
\hline Griffonia simplicifolia lectin II & GSL II & $N$-acetylglucosamine & $\alpha$ - and $\beta$ - GlcNAc \\
\hline Concavaline A & Con A & $\begin{array}{l}\text { Mannose/ D-glucose/ } N \text {-acetylglucosa- } \\
\text { mine }\end{array}$ & $\begin{array}{l}{[\operatorname{GlcNAc}(\beta 1-2) \operatorname{Man}(\alpha 1-6)]} \\
{[\operatorname{GlcNAc}(\beta 1-2) \operatorname{Man}(\alpha 1-3)] \operatorname{Man}(\beta 1-} \\
4)] \operatorname{GlcNAc}(\alpha)>\operatorname{D-Man}(\alpha-)> \\
\text { D-Glc }(\alpha-)>\operatorname{GlcNAc}(\alpha-)\end{array}$ \\
\hline Lens culinaris agglutinin & LCA & & $\begin{array}{l}{[\operatorname{GlcNAc}(\beta 1-2) \operatorname{Man}(\alpha 1-6)]} \\
{[\operatorname{GlcNAc}(\beta 1-2) \operatorname{Man}(\alpha 1-3)][\operatorname{Man}(\beta 1-4)} \\
\operatorname{Man}(\alpha-)]\end{array}$ \\
\hline Pisum sativum agglutinin & PSA & & $\begin{array}{l}{[\operatorname{GlcNAc}(\beta 1-2) \operatorname{Man}(\alpha 1-6)]} \\
{[\operatorname{GlcNAc}(\beta 1-2) \operatorname{Man}(\alpha 1-3)] \operatorname{Man}(\beta 1-} \\
4)] \operatorname{GlcNAc}(\alpha)>\operatorname{D-Man}(\alpha-)> \\
\text { D-Glc }(\alpha-)>\operatorname{GlcNAc}(\alpha-)\end{array}$ \\
\hline Phaseolus vulgaris erythro agglutinin & PHA-E & Galactose/ $N$-cetylglucosamine/Mannose & $\begin{array}{l}\text { Gal } \beta 4 \text { GlcNAc } \beta 2 M a n \alpha 6 ;(\text { GlcNAc } \beta 4) ; \\
\text { (GlcNAc } \beta 4 M a n \alpha 3) ; \operatorname{Man} \beta 4\end{array}$ \\
\hline Phaseolus vulgaris leuco agglutinin & PHA-L & & $\begin{array}{l}\text { Gal } \beta 4 \text { GlcNAc } \beta 6 \text {; (GlcNAc } \beta 2 M a n \alpha 3) \text {; } \\
\text { Man } \alpha 3\end{array}$ \\
\hline Dolichos biflorus agglutinin & DBA & $N$-acetylgalactosamine & TER $\alpha$-GalNAc. $\alpha$-linked GalNac \\
\hline Vicia villosa agglutinin & VVA & & TER $\alpha$ - or $\beta$-linked GalNAc \\
\hline Erythrina cristagalli lectin & ECL & $\begin{array}{l}N \text {-acetillactosamine/ } N \text {-acetylgalactosa- } \\
\text { mine }\end{array}$ & $\begin{array}{l}N \text {-acetyllactosamine }>\text { Lactose }>\mathrm{N} \text {-acetyl- } \\
\text { D-galactosamine }>\text { Galactose }\end{array}$ \\
\hline Sambucus nigra agglutinin & SNA & Sialic acid/ Galactose/ $N$-acetylgalac- & Neu5Ac $(\alpha-2,6)$ linkage \\
\hline Maackia amurensis lectin II & MAL II & tosamine & Neu5Ac $(\alpha-2,3)$ linkage \\
\hline Wheat germ agglutinin & WGA & $\begin{array}{l}\text { Chitobiose/ } N \text {-acetylglucosamine/ } \\
N \text {-acetylgalactosamine }\end{array}$ & $\begin{array}{c}{[\mathrm{GlcNac} \beta(1,4)] 2 \mathrm{GlcNac}>\operatorname{GlcNac} \beta(1,4)} \\
\text { GlcNac }>\text { GlcNac }>\text { Neu5Ac }>\text { GalNAc }\end{array}$ \\
\hline Succinylated wheat germ agglutinin & sWGA & & $\begin{array}{l}{[\mathrm{GlcNac} \beta(1,4)] 2 \text { GlcNac }>\operatorname{GlcNac} \beta(1,4)} \\
\text { GlcNac }>\text { GlcNac }>\text { GalNAc }\end{array}$ \\
\hline Solanum tuberosum (potatoe) lectin & STL & & $\begin{array}{l}{[\text { GlcNAc } \beta(1,4)] 3 \text { Glc- }} \\
\text { NAc }>[\text { GlcNAc } \beta(1,4)] 2 \text { Glc- } \\
\text { NAc }>\text { GlcNAc } \beta(1,4) \text { GlcNAc }\end{array}$ \\
\hline Datura stramonium lectin & DSL & & Chitotriose $>$ Chitobiose $>$ GlcNAc \\
\hline Lycopersicon esculentum (tomato) lectin & LEL & & $\begin{array}{l}\text { Chitin-binding lectins. GlcNAc } \beta(1,4) \\
\text { GlcNAc oligomers up to } 4 \text { carbohydrate } \\
\text { units }\end{array}$ \\
\hline Jacalin & Jacalin & Galactose/ $N$-acetylgalactosamine & $\begin{array}{l}\text { Bind only O-glycosidically linked oli- } \\
\text { gosaccharides, preferring the structure } \\
\text { galactosyl }(\beta-1,3) N \text {-acetylgalactosamine }\end{array}$ \\
\hline Peanut agglutinin & PNA & & Lactose $>\beta$ - D-Galactose \\
\hline Soybean agglutinin & SBA & & TER $\alpha$ - e $\beta$ - GalNAc \\
\hline $\begin{array}{l}\text { Griffonia (Bandeiraea) simplicifolia } \\
\text { lectin I }\end{array}$ & GSL I & & $\begin{array}{l}\alpha \text { - D-Galactoside and } \alpha \text {-linked galactose } \\
\text { oligosaccharides. } \alpha \text {-GalNAc-O-Ser/Thr. } \\
\alpha \text { Gal, } \alpha \text { GalNAc }\end{array}$ \\
\hline Ricinus communis agglutinin I & RCA I/RCA 120 & & $\begin{array}{l}\beta \text {-galactose residues, with a preference for } \\
\text { terminal sugars }\end{array}$ \\
\hline Ulex europaeus agglutinin I & UEA I & Fucose & $\alpha$-linked Fucose \\
\hline
\end{tabular}

Gal galactose, GalNac N-acetylgalactosamine, Glc Glucose, GlcNac N-acetylglucosamine, Man mannose, NeuAc sialic acid, Ser serine, TER terminal, $T h r$ threonine

(Thompson et al. 2011). Subsequently, the wells were washed three times for $5 \mathrm{~min}$ with Tris-buffered saline, $\mathrm{pH}$ 7.6, containing $0.05 \%$ Tween 20 (TBS-T). Wells were then incubated with the lectins $(1 \mu \mathrm{g} / \mathrm{ml})$ prepared in TBS-Tions (supplemented with $1 \mathrm{mM} \mathrm{CaCl}, 1 \mathrm{mM} \mathrm{MnCl}_{2}, 1 \mathrm{mM}$
$\mathrm{MgCl}_{2}, 1 \mathrm{mM} \mathrm{ZnCl}$ ) for $1 \mathrm{~h}$ at $37{ }^{\circ} \mathrm{C}$. Then, wells were washed as described above and incubated with horseradish peroxidase-conjugated streptavidin (Vector Laboratories, USA) diluted 1:40,000 in TBS-T for $1 \mathrm{~h}$ at $37^{\circ} \mathrm{C}$. Then, wells were TBS-T washed, followed by incubation with 
TMB Substrate Solution (1- Step Ultra TMB Elisa; Thermo Fisher Scientific, USA) for 5 min at RT. The reaction was stopped with $2 \mathrm{M}$ sulfuric acid and the absorbance measured at $450 \mathrm{~nm}$ in a spectrophotometer (Bio Tek Synergy HT, USA). For each lectin, eight replicate absorbances were obtained using disc and stem extracts. Control reactions were performed by skipping protein addition to get a blank and using lectins saturated with their inhibitory monosaccharide (see Table S1). The statistical significance of differences between disc and stem extracts was determined by two-sample $t$ test or Mann-Whitney $U$ test. $P<0.05$ was considered to indicate a statistically significant difference. Normality was checked using Shapiro Wilks, as well as, homoscedasticity using $F$ test or Levene test.

\section{Lectin blotting}

Glycoproteins separation was performed by SDS-PAGE based on molecular weight. Applied voltage during the run was constant between 50 and $100 \mathrm{~V}$. Afterwards, glycoproteins were transferred to a polyvinylidene fluoride (PVDF) membrane and then blocked with $10 \mathrm{mM}$ Tris buffered saline $\mathrm{pH} 8$ containing $0.05 \%$ Tween-20 and 3\% BSA (TBS-T-BSA) at $4{ }^{\circ} \mathrm{C}$, overnight with constant rotation. Membranes were incubated for $1 \mathrm{~h} 30 \mathrm{~min}$ with 1 of the 22 biotinylated lectins diluted at a concentration of $1 \mu \mathrm{g} /$ $\mathrm{ml}$ in TBS-T-BSA supplemented with $1 \mathrm{mM} \mathrm{CaCl} 2,1 \mathrm{mM}$ $\mathrm{MnCl}_{2}, 1 \mathrm{mM} \mathrm{MgCl}, 1 \mathrm{mM} \mathrm{ZnCl}$ (TBA-T-BSA ions), followed by 5 washes in TBS-T. The membrane was then incubated with horseradish peroxidase-conjugated streptavidin (Vector Laboratories) diluted 1:5000 in TBS-T-BSA for $1 \mathrm{~h}$, in the dark with rotation. After 5 washes in TBS-T, glycoproteins were visualised using an ECL immunoblot detection system (Amersham GE Healthcare, UK) and a CCD imager ImageQuant LAS 500 (GE Healthcare, UK).

\section{Results}

Using lectin histochemistry, we were able to localise glycans in tube foot sections and in the secreted adhesive, taking advantage of their specific interaction with the 22 tested lectins. This was complemented with an enzyme linked lectin assay (ELLA) microplate assay, to obtain an estimate of the abundance of glycans (both free and/or conjugated) in adhesive discs versus non-adhesive stems protein extracts. Finally, lectin blotting was used to distinguish which glycans are covalently linked to proteins.

This approached pin-pointed 5 lectins, GSL II (Griffonia simplicifolia lectin II), WGA (wheat germ agglutinin), STL (Solanum tuberosum lectin), LEL (Lycopersicon esculentum lectin) and SBA (soybean agglutinin) that cumulatively: (i) labelled exclusively the disc adhesive epidermis and the adhesive footprints, (ii) detected glycans whose abundance was significantly higher in adhesive discs than stems (1.4 to 2.9-fold) and (iii) strongly labelled glycoproteins in the adhesive discs that are absent in the non-adhesive stems (Table 2, Figs. 2-6).

GSL II detects $\alpha$ - and $\beta$ - $\mathrm{N}$-acetylglucosamine residues (Table 1). It labelled strongly all the adhesive epidermis, being more intense at the base of the disc epidermis where the secretory cells bodies are located. Some weak labelling of the cuticle was also observed (Fig. 2a). At higher magnification, it was possible to see that the observed labelling was not uniform but presented spread dots which might correspond to secretory granules (Fig. 3a). This lectin also labelled the adhesive footprint being more intense in thicker areas (Fig. 4a). In terms of abundance, the adhesive discs extracts had more $\mathrm{N}$-acetylglucosamine than the stem ones (2.4-fold; Fig. 5, Table 2), and this glycan seems to be present in two glycoproteins, with apparent molecular weights of 72 and $>180 \mathrm{kDa}$, that are exclusively present in the discs (Fig. 6, Table 2).

WGA, STL and LEL also detect $N$-acetylglucosamine (GlcNac) but in a specific chitobiose arrangement, i.e., a dimer of $\beta$-1,4-linked glucosamine units. WGA that detects up to two GlcNac $\beta(1,4)$ GlcNac units (Table 1), labelled very strongly all the disc adhesive epidermis and the cuticle. Some weak staining was also visible in the non-adhesive stem epidermis (Fig. 2b). STL that detects up to three GlcNac $\beta(1,4)$ GlcNac units (Table 1) presented a similar labelling but more intense at the base of the central part disc adhesive epidermis (Fig. 2c). LEL that detects up to four GlcNac $\beta(1,4)$ GlcNac units (Table 1$)$ produced a very specific and strong labelling of the adhesive epidermis, staining what seems to be the ducts of adhesive cells (Fig. 2d). This was verified at higher magnification, being possible to observe the labelling of spherical structures, most likely secretory granules, packed within ducts that widen at the apex of the disc. LEL produced a much more specific labelling than WGA and STL (compare Fig. 3b-d), targeting only the outer rim of the granules were labelled (Fig. 3e). The three lectins also labelled the adhesive footprints, this staining being particularly intense with LEL (Fig. 4b-d). In terms of abundance, the ELLAs with the 3 lectins showed that adhesive disc extracts have a significantly higher amount of chitobiose than the stem (1.4- and 2.9-fold) (Fig. 5, Table 2), and lectin blotting evidenced that this glycan is conjugated with a high molecular weight glycoprotein $(>180 \mathrm{kDa})$ that is only present in the adhesive discs. WGA also detected another glycoprotein with an apparent molecular weight of $30 \mathrm{kDa}$ that seems to be exclusively present in the adhesive discs. (Fig. 6, Table 2).

As for SBA, it detects terminal $\alpha$ - e $\beta$ - $N$-acetylgalactosamine (GalNac). It labelled strongly the cuticle as well as small ellipsoid structures in adhesive epidermis 
Table 2 Intensity of the lectin labelling obtained for sea urchin Paracentrotus lividus tube foot disc and stem sections and protein extracts, as well as, adhesive footprints, using 3 complementary techniques and 22 biotinylated lectins

\begin{tabular}{|c|c|c|c|c|c|c|c|}
\hline \multirow[t]{2}{*}{ Lectin } & \multicolumn{3}{|c|}{ Adhesive disc } & \multicolumn{3}{|c|}{ Non-adhesive stem } & \multirow{2}{*}{$\begin{array}{l}\text { Adhesive } \\
\text { secretion } \\
\text { LH }\end{array}$} \\
\hline & LH & ELLA & LB & $\mathrm{LH}$ & ELLA & LB & \\
\hline GSL II & $\begin{array}{l}+++ \\
\mathrm{AE}, \mathrm{Cu}\end{array}$ & $\begin{array}{l}++ \\
2.4-\text { fold }\end{array}$ & $\begin{array}{l}+ \\
72 \text { and }>180 \mathrm{kDa}\end{array}$ & - & + & + & + \\
\hline Con A & ++ & $\begin{array}{l}+++ \\
1.1 \text {-fold }\end{array}$ & +++ & ++ & +++ & +++ & + \\
\hline LCA & ++ & $\begin{array}{l}+++ \\
1.5 \text {-fold }\end{array}$ & $\begin{array}{l}++ \\
72 \text { and } 135 \mathrm{kDa}\end{array}$ & ++ & +++ & + & + \\
\hline PSA & + & $\begin{array}{l}++ \\
1.4 \text {-fold }\end{array}$ & $\begin{array}{l}++ \\
72 \text { and } 135 \mathrm{kDa}\end{array}$ & + & ++ & + & + \\
\hline PHA-E & + & $\begin{array}{l}++ \\
1.0 \text {-fold }\end{array}$ & - & + & ++ & - & + \\
\hline PHA-L & ++ & $\begin{array}{l}++ \\
1.6-\text { fold }\end{array}$ & $\begin{array}{l}++ \\
>180 \mathrm{kDa}\end{array}$ & ++ & ++ & + & + \\
\hline DBA & + & $\begin{array}{l}+++ \\
1.4-\text { fold }\end{array}$ & $\begin{array}{l}++ \\
72 \text { and } 135 \mathrm{kDa}\end{array}$ & + & ++ & + & - \\
\hline VVA & $\begin{array}{l}++ \\
\mathrm{AE}, \mathrm{Cu}\end{array}$ & $\begin{array}{l}++ \\
1.6-\text { fold }\end{array}$ & - & - & + & - & - \\
\hline ECL & + & $\begin{array}{l}++ \\
1.4-\text { fold }\end{array}$ & - & + & + & - & + \\
\hline SNA/EBL & + & $\begin{array}{l}++ \\
2.0-\text { fold }\end{array}$ & $\begin{array}{l}++ \\
72 \text { and } 135 \mathrm{kDa}\end{array}$ & + & + & - & - \\
\hline MAL II & ++ & $\begin{array}{l}+++ \\
1.6 \text {-fold }\end{array}$ & - & ++ & ++ & - & - \\
\hline WGA & $\begin{array}{l}+++ \\
\mathrm{AE}, \mathrm{Cu}\end{array}$ & $\begin{array}{l}++ \\
2.9 \text {-fold }\end{array}$ & $\begin{array}{l}++ \\
30 \text { and }>180 \mathrm{kDa}\end{array}$ & + & + & + & + \\
\hline sWGA & + & $\begin{array}{l}+ \\
1.0-\text { fold }\end{array}$ & $\begin{array}{l}+ \\
72,135 \text { and }>180 \mathrm{kDa}\end{array}$ & + & + & + & - \\
\hline STL & $\begin{array}{l}+++ \\
\mathrm{AE}, \mathrm{Cu}\end{array}$ & $\begin{array}{l}++ \\
1.4-\text { fold }\end{array}$ & $\begin{array}{l}++ \\
>180 \mathrm{kDa}\end{array}$ & + & ++ & + & + \\
\hline DSL & + & $\begin{array}{l}++ \\
1.6 \text {-fold }\end{array}$ & +++ & + & ++ & +++ & + \\
\hline LEL & $\begin{array}{l}+++ \\
\mathrm{AE}\end{array}$ & $\begin{array}{l}+ \\
1.4 \text {-fold }\end{array}$ & $\begin{array}{l}++ \\
>180 \mathrm{kDa}\end{array}$ & - & + & - & ++ \\
\hline Jacalin & - & $\begin{array}{l}++ \\
1.2 \text {-fold }\end{array}$ & - & - & ++ & - & - \\
\hline PNA & + & $\begin{array}{l}++ \\
1.8 \text {-fold }\end{array}$ & - & + & + & - & - \\
\hline SBA & $\begin{array}{l}+++ \\
\mathrm{AE}, \mathrm{Cu}\end{array}$ & $\begin{array}{l}++ \\
2.0 \text {-fold }\end{array}$ & $\begin{array}{l}++ \\
72 \text { and } 135 \mathrm{kDa}\end{array}$ & + & + & + & + \\
\hline GSL I & $\begin{array}{l}++ \\
\mathrm{Cu}\end{array}$ & $\begin{array}{l}++ \\
2.4-\text { fold }\end{array}$ & - & - & + & - & + \\
\hline RCA I & + & $\begin{array}{l}++ \\
2.1 \text {-fold }\end{array}$ & - & + & + & - & + \\
\hline UEA I & + & $\begin{array}{l}++ \\
1.2 \text {-fold }\end{array}$ & - & + & ++ & - & - \\
\hline
\end{tabular}

For lectin histochemistry (LH), results are presented in terms of labelling intensity and for the disc, the specific labelled tissues are also mentioned. For enzyme-linked lectin assay (ELLA), results are presented in terms of absorbance intensity and also the ratio between the absorbances measured in the disc versus the stem. For lectin blotting (LB), results are presented in terms of intensity of band labelling as well as the approximate apparent molecular weight (in $\mathrm{kDa}$ ) of the observed glycoproteins. In all techniques, lectins intensity is identified as-no staining, + weak staining, ++ strong staining, +++ very strong staining $A E$ adhesive epidermis, $C u$ cuticle 
(Fig. 2e). At higher magnification, it was possible to see that this lectin labelled specifically the microvilosities at the apex of the disc epidermis and the cytoplasm of widespread epidermal cells (Fig. 3f). Labelling of adhesive footprints with SBA produced a faint dotted staining (Fig. 4e). GalNac abundance was significantly higher in adhesive disc extracts in comparison with the non-adhesive stems (twofold) (Fig. 5, Table 2), and this residue seems to be conjugated, since two distinctive disc glycoproteins with apparent molecular weights of 72 and $135 \mathrm{kDa}$ were detected (Fig. 6, Table 2).

Interestingly, these two glycoproteins were also strongly labelled by LCA (Lens culinaris agglutinin), PSA (Pisum sativum agglutinin), DBA (Dolichos biflorus agglutinin) and SNA (Sambucus nigra agglutinin) (Fig. S11, Table 2). LCA and PSA both detect mannose-linked $N$-acetylglucosamine, while DBA detects $\alpha$-GalNAc and SNA detects sialic acids. This indicates that these glycoproteins probably possess multiple glycosylation sites bound to $\mathrm{N}$-acetylgalactosamine, mannose linked $N$-acetylglucosamine and sialic acids. However, the labelling of the tube foot sections, and adhesive footprints was very weak (Figs. S1, S3, S5 and S9, Table 2), indicating that the glycans detected by these lectins are much less abundant than the ones detected by SBA.

\section{Discussion}

Glycan and protein glycosylation have been gaining relevance in studies concerning the adhesion of a wide range of organisms, covering permanent (mussels, barnacles, algal spores), transitory (limpets, marsh periwinkle) or temporary (sea stars, flatworms, ascidian larvae) adhesion.

The present study demonstrates the involvement of glycoproteins in sea urchin temporary adhesion. Using a battery of 22 lectins, we investigated the location, abundance and protein conjugation of several glycans residues. Five lectins (GSL II, WGA, STL, LEL and SBA) specifically labelled glycans relevant for $P$. lividus adhesion, demonstrated by their ability to label the disc adhesive epidermis and the adhesive footprints, the significant higher abundance of the detected glycans in the adhesive disc in comparison with the non-adhesive stem, and the detection of several disc specific glycoproteins (Fig. 7).

Four of these lectins (GSLII, WGA, STL and LEL) detect $N$-acetylglucosamine, indicating that this glycan is part of the secreted adhesive. Within these, LEL specifically labelled the outer rim of spherical structures packed within ducts that widen at the apex of the disc (Fig. 3d-e). This observation is consistent with the labelling of adhesive secretory granules within the characteristic sea urchin 'apical tuft' secretory cells, being released at the tip of microvillar-like cell projections arranged in a tuft at the cell apex. Indeed, it was shown that $P$. lividus adhesive epidermis presents two types of adhesive granules: homogeneous granules (500-700 $\mathrm{nm}$ in diameter) apparently made up of only one material in the central part of the disc and dense-cored granules (300-500 $\mathrm{nm}$ in diameter) consisting of an electron-denser core surrounded by less dense material in the remaining area (Santos and Flammang 2006). Therefore, our results indicate the presence of $\mathrm{N}$-acetylglucosamine in the form of chitobiosis [GlcNac $\beta(1,4) \mathrm{GlcNac}]$, most likely 4 units, in the outer rim of the more abundant adhesive granules, as well as, in the less abundant homogenous granules. The function of these two types of granules in P. lividus is not fully understood, but it could provide different adhesive power within the same tube foot. In fact, during tube foot extension, the central part of the disc forms a conical projection due to the increased hydrostatic pressure exerted by the ambulacral fluid (Flammang and Jangoux 1993). Therefore, it can be hypothesized that the homogenous granules, present at the disc central conical tip, are composed only by glycans and their content is released during substrate exploration that requires less adhesive strength. Once the animal finds a suitable substrate to attach, the content of heterogenous granules would be released containing glycoproteins, providing increased cohesion and adhesion.

These four lectins also label a high molecular weight glycoprotein (apparent molecular weight $>180 \mathrm{kDa}$ ) that is exclusively present in adhesive disc extracts. These results together with the fact that this glycan is secreted into the adhesive footprint, being localized exclusively in the disc and more specifically in the outer rim of spherical structures packed inside ducts ending in apical tufts, are very strong indications that this glycoprotein is most likely the main component of $P$. lividus adhesive secretion. This would be in agreement with recent results showing that temporary adhesion relies on the secretion of large proteins (Hennebert et al. 2014; Pjeta et al. 2019; Wunderer et al. 2019), and the detection of glycoproteins segregated in the outer rim of the adhesive secretory granules in other aquatic temporary-attaching organisms like the flatworm Macrostomum lignano (detected by PNA_-Peanut agglutinin; Lengerer et al. 2016, Wunderer et al. 2019) and the sea star Asterina gibbosa (detected by Jacalin; Lengerer et al. 2018). Taken together, these results clearly demonstrate the relevance of glycoproteins in temporary adhesion, although with variations of the linked glycan residues.

One lectin (SBA) detected $N$-acetylgalactosamine in the adhesive footprint and in the disc adhesive epidermis, but this labelling seems to target microvilosities and the cytoplasm of abundant epidermal cells. In fact, epidermal cells usually occur in clusters of four types of cells (support, sensory cells, adhesive secretory and de-adhesive cells), 

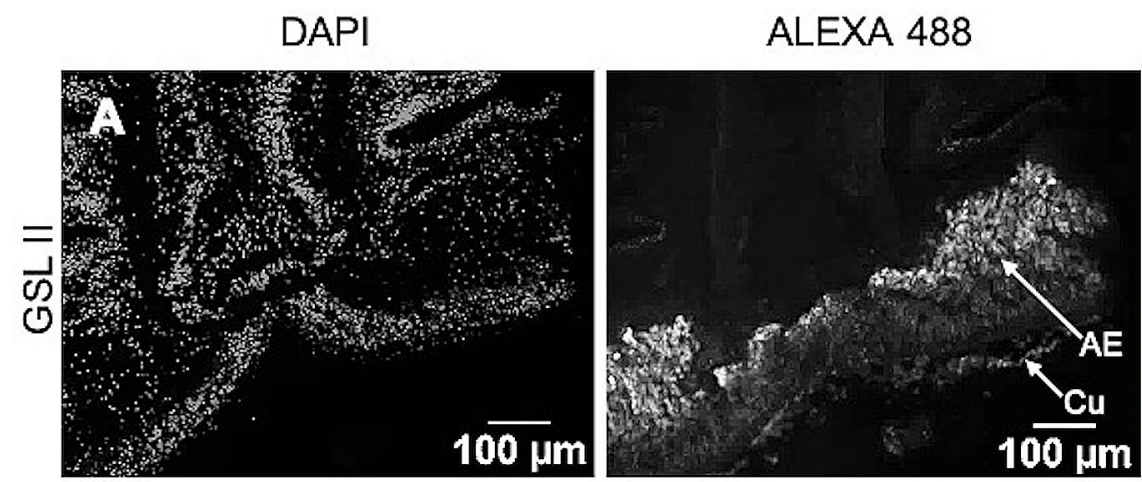

MERGE
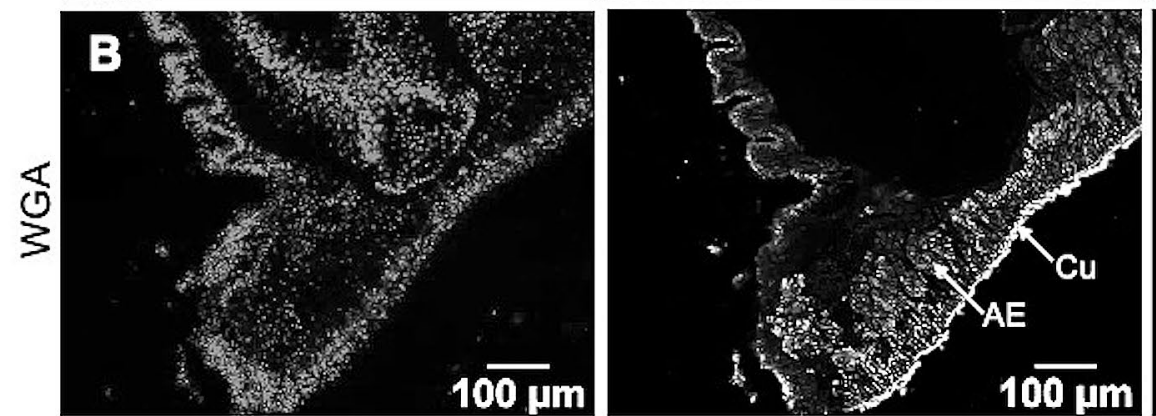

$100 \mathrm{um}$
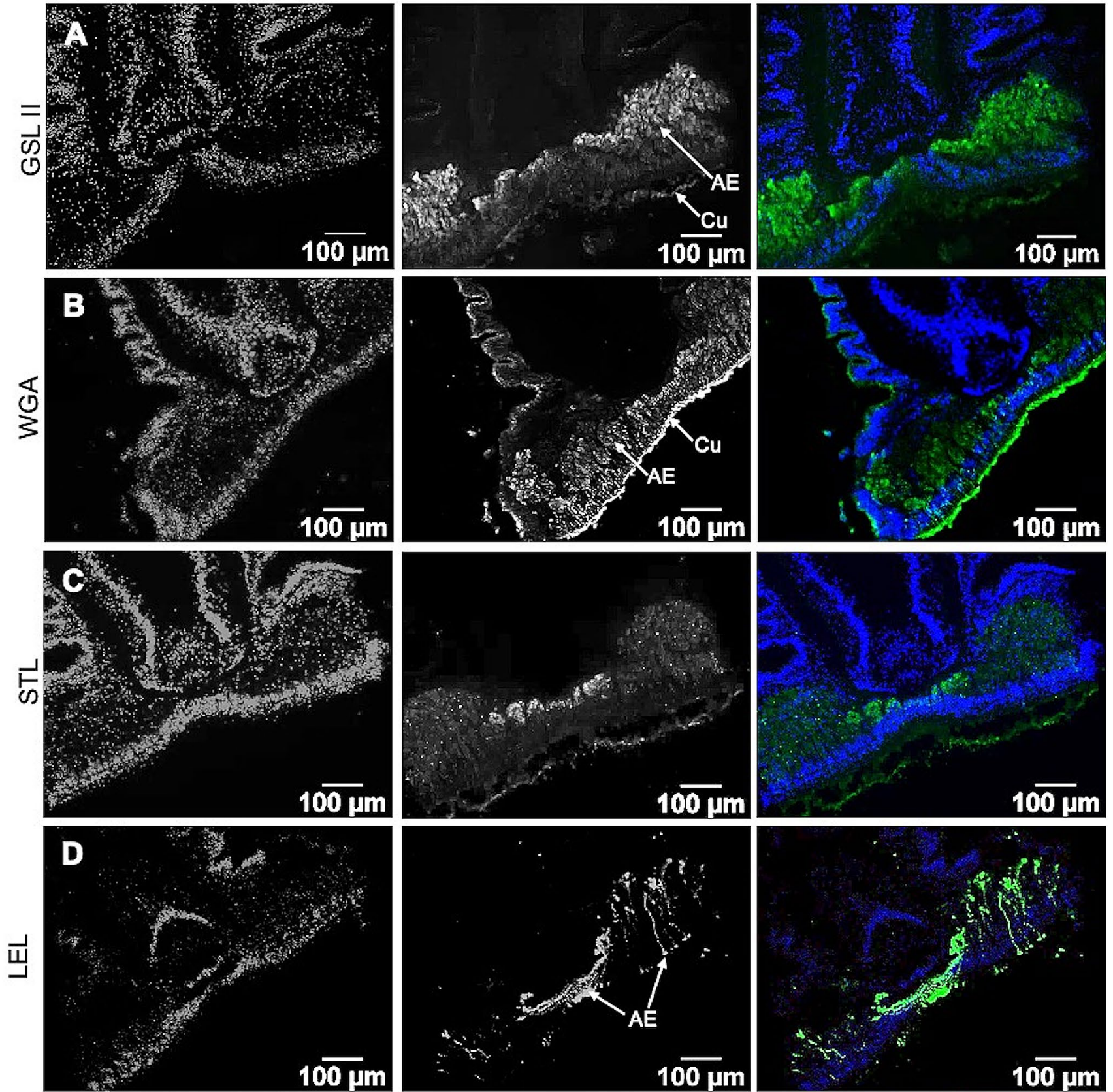

$100 \mathrm{ym}$
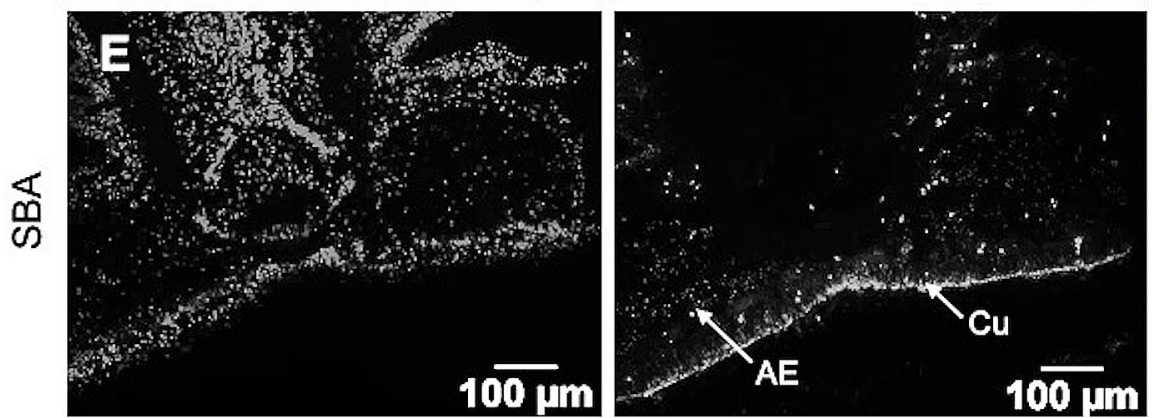

$100 \mathrm{um}$

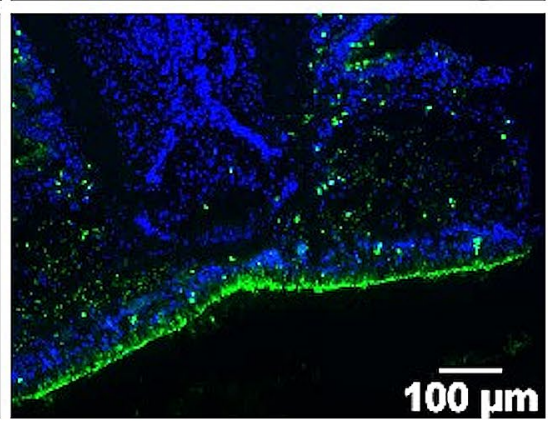


4Fig. 2 Labelling of Paracentrotus lividus tube foot sections with the 5 most relevant lectins. Lectin histochemistry images obtained by fluorescence microscopy. The disc surface is oriented downwards towards the right in all the pictures. Detection of $N$-acetylglucosamine using GSL II (a); chitobiosis using WGA (b), STL (c) and LEL (d), and $N$-acetylgalactosamine using SBA (e). GSL II Griffonia simplicifolia lectin II, LEL Lycopersicon esculentum lectin, SBA Soybean agglutinin, STL Solanum tuberosum lectin, WGA wheat germ agglutinin

separated by connective tissue protrusions. All epidermal cells are flask-shaped, with an enlarged nucleus, and a long, narrow apical neck extending up to the disc surface (Santos and Flammang 2006). Being support cells the most abundant cell type in the disc and possessing a characteristic enlarged apical neck with numerous microvilli, the referred lectin seems to be labelling $N$-acetylgalactosamine contained in their cytoplasm and microvilosities, thus being less relevant for adhesion. In addition, this glycan was found to be conjugated with two glycoproteins with apparent molecular weights of 72 and $135 \mathrm{kDa}$. Proteins with the same apparent molecular weight were also detected by other lectins (LCA, PSA, DBA and SNA), indicating that these two glycoproteins are possibly highly glycosylated possessing $\mathrm{N}$-acetylgalactosamine, mannose-linked $N$-acetylglucosamine and sialic acid residues. It must be stressed that, the detected glycoproteins can influence adhesion indirectly. This has been shown in flatworms, where the knock-down of a single support-cell-specific protein led to a non-adhesive phenotype, without influencing the production or secretion of the adhesive proteins (Lengerer et al. 2014, Lengerer et al. 2018, Pjeta et al. 2019).

If we compare the available information concerning the techniques used to study glycans involvement in animals that use temporary wet adhesion (Fig. 7) we can conclude that most results were obtained by lectin histochemistry. However, it is advisable to use complementary techniques, because as previously stressed by Hennebert et al. (2011), different techniques provide distinct information since glycans are chemically fixed in histological sections, occur in their native state in glue prints, and are denatured in protein extracts.

Research on the ascidian Ciona intestinalis has shown that larvae papillae secrete a temporary adhesive that contains $O$-glycans (detected by PNA) and $\mathrm{N}$-glycans (detected by PHA-E-Phaseolus vulgaris erythron agglutinin and GSL II) with galactoses and $\mathrm{N}$-acetylglucosamines (Zeng et al. 2019).

Flatworm temporary adhesion has been studied in three species. In Macrostomum lignano, the adhesive organ is strongly labelled by two lectins (PNA and RCA-Ricinus communis agglutinin), but PNA was shown to target specifically an adhesive glycoprotein (Mlig-ap2), indicating that it contains galactose-linked to $\mathrm{N}$-acetylgalactosamine residues (Wunderer et al. 2019). In Schmidtea mediterranea, 12 lectins strongly labelled the adhesive organ (Zayas et al. 2010), while in Minona ileanae footprints 11 lectins showed specific labelling of the secreted adhesive (Pjeta et al. 2019), indicating the presence of various sugar moieties possibly relevant for temporary adhesion in both species.

As for sea stars, glycans involvement in temporary adhesion has been investigated in two species. The best studied one, A. rubens, secretes an adhesive that contains glycoproteins (Sfp-210 and Sfp-290) with N-glycans (detected by ConA) and O-glycans (detected by PNA) with fucoselinked to galactose (detected by UEA I), sialic acid linked to $\mathrm{N}$-acetylgalactosamine (MAL II-Maackia amurensis lectin II), and also $N$-acetylgalactosamine and galactose residues (detected by RCA I, GSL I, DBA, and SJASophora japonica agglutinin). It also contains large glycoconjugates enclosing sialic acids (label with WGA but not sWGA) (Hennebert et al. 2011). In Asterina gibbosa, 15 lectins labelled structures in the area of the duo-gland adhesive system, but only one (ConA) also labelled secreted adhesive, indicating the presence of glycoconjugates with $\alpha$-linked mannose (Lengerer et al. 2018).

In the sea urchin P. lividus, we showed that its adhesive secretion possesses glycoproteins with $N$-glycans (detected by GSL II) and O-glycans (detected by SBA), more specifically a glycoprotein $(>180 \mathrm{kDa})$ with $\mathrm{N}$-acetylglucosamine oligomers (detected by LEL), and two glycoproteins (72 and $135 \mathrm{kDa}$ ) with terminal $N$-acetylgalactosamine (detected by SBA). It is important to mention that although the lectin-blots label single bands, these might correspond to a single glycoprotein or a mixture of glycoproteins with close molecular weights. The obtained histochemical labelling, points to an adhesive function of the high molecular weight glycoprotein, while the two remaining glycoproteins would be associated with support rather than secretory cells. This assumption is further supported by the presence of $N$-(beta- $n$-acetylglucosaminyl)-L-asparaginase highly over-expressed in the adhesive disc (fourfold) which was pointed as a possible component of the de-adhesive secretion (Lebesgue et al. 2016). This could indicate that sea urchin's duo-glandular adhesive system is composed by an adhesive asparagine-linked glycoprotein rich in $\mathrm{N}$-acetylglucosamine oligomers and a de-adhesive $N$-(beta- $n$-acetylglucosaminyl)-L-asparaginase capable of cleaving the GlcNAc-Asn bond which joins the oligosaccharides to the protein moiety. Indeed, for animals with 

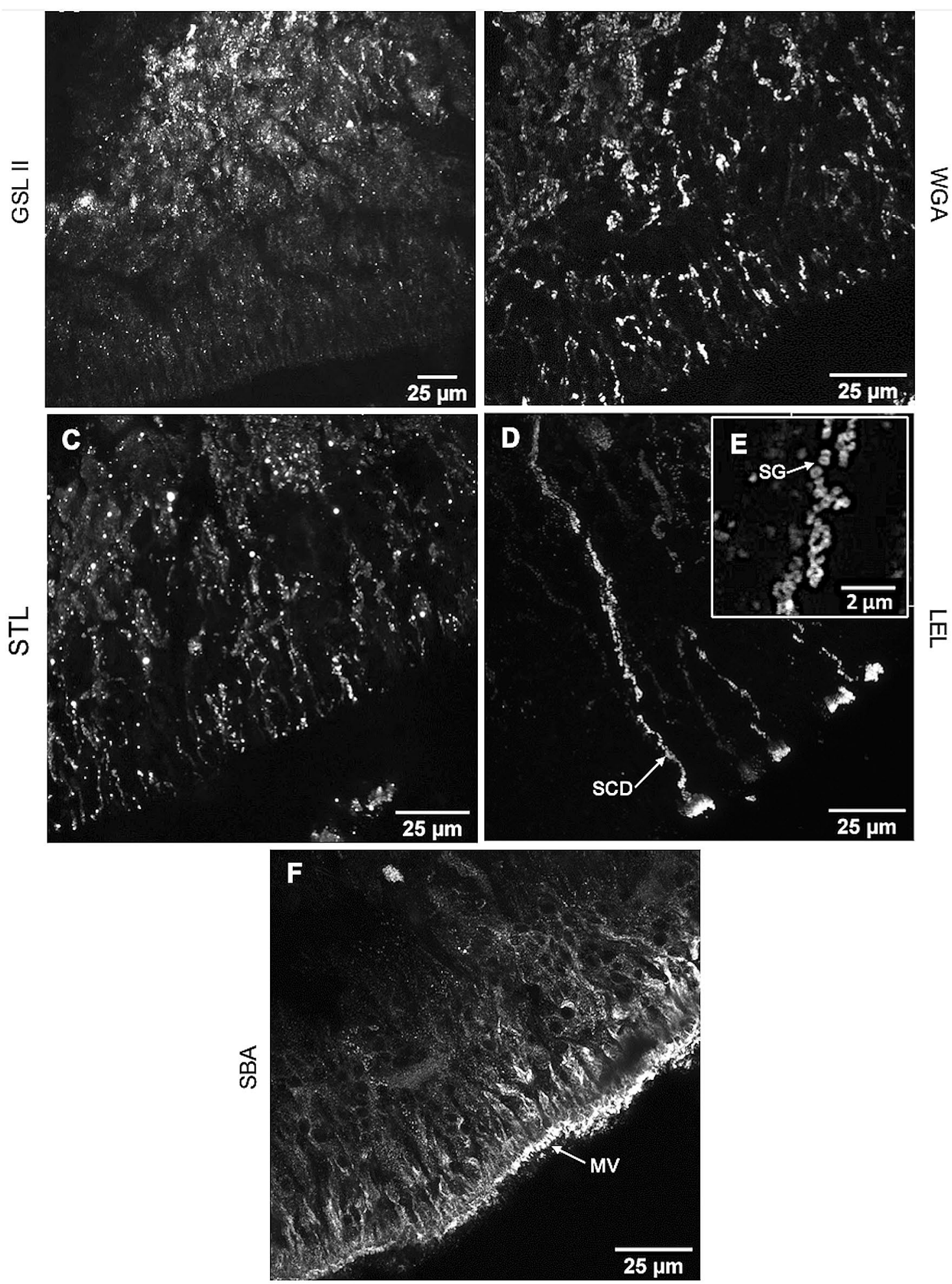

Fig. 3 Detailed labelling of Paracentrotus lividus tube foot disc epidermis using the 5 most relevant lectins. Lectin histochemistry images obtained by confocal microscopy. The disc surface is oriented downwards towards the right in all the pictures. Detection of $N$-acetylglucosamine using GSL II (a); chitobiosis using WGA, STL and LEL (b-d, respectively) and $N$-acetylgalactosamine using SBA (f). Detail of secretory granules (digital zoom) detected by LEL (e). GSL II Griffonia simplicifolia lectin II, LEL Lycopersicon esculentum lectin, $M V$ microvilosity, $S B A$ Soybean agglutinin, $S C D$ secretory cell duct, $S G$ secretory granule, $S T L$ Solanum tuberosum lectin, $W G A$ wheat germ agglutinin 

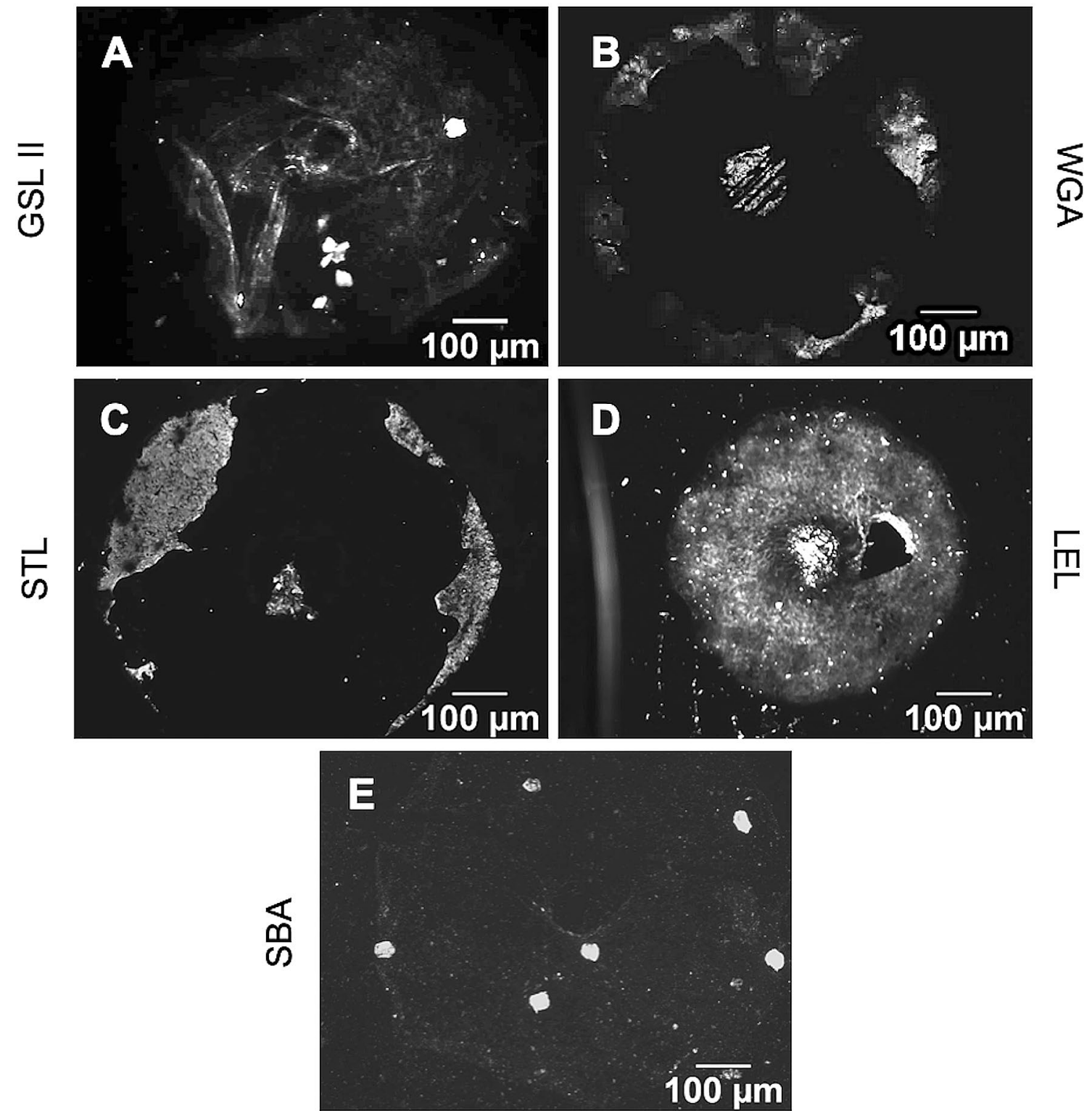

Fig. 4 Labelling Paracentrotus lividus adhesive footprints using the 5 most relevant lectins. Lectin histochemistry images obtained by fluorescence microscopy. Detection of $\mathrm{N}$-acetylglucosamine using GSL II (a); chitobiosis using WGA (b), STL (c) and LEL (d), and $N$-acetyl- galactosamine using SBA (e). GSL II Griffonia simplicifolia lectin II, LEL Lycopersicon esculentum lectin, SBA Soybean agglutinin, STL Solanum tuberosum lectin, $W G A$ wheat germ agglutinin 


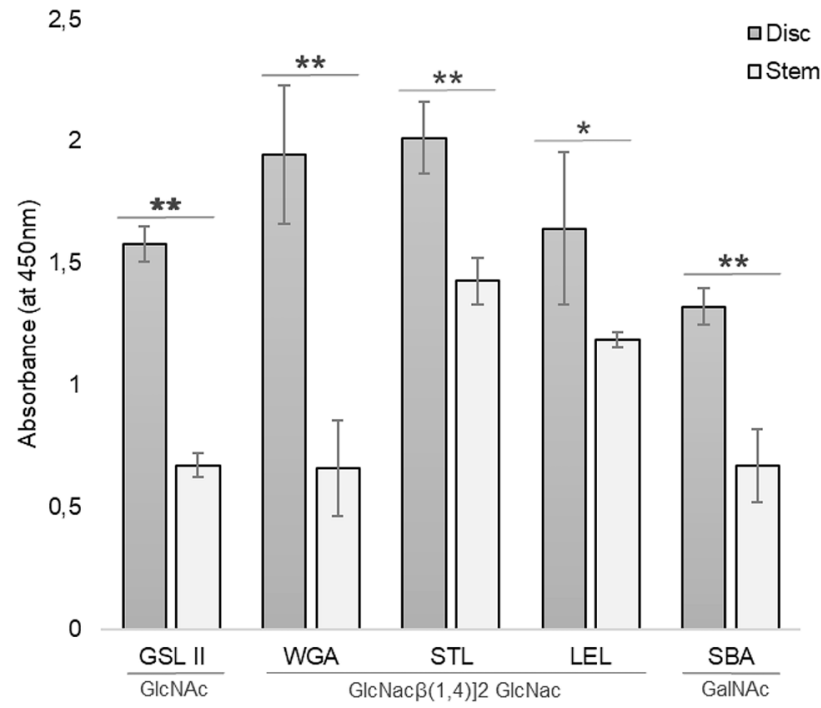

Fig. 5 Glycan abundance in Paracentrotus lividus tube feet disc and stem extracts obtained with the 5 most relevant lectins. Enzyme linked lectin assay comparing the obtained absorbance values. GSL II was used to detect the presence of $N$-acetylglucosamine; WGA, STL and LEL to detect chitobiosis and SBA to detect $N$-acetylgalactosamine in the extracts. Each bar represents the mean and the standard deviation $(N=8)$. Parametric $T$-tests were performed to compare absorbance values for each lectin; ${ }^{*} p<0.05$ and ${ }^{* *} p<0.001$. GSL II Griffonia simplicifolia lectin II, Gal galactose, GalNac N-acetylgalactosamine, GlcNac N-acetylglucosamine, LEL Lycopersicon esculentum lectin, SBA Soybean agglutinin, STL Solanum tuberosum lectin, $W G A$ wheat germ agglutinin

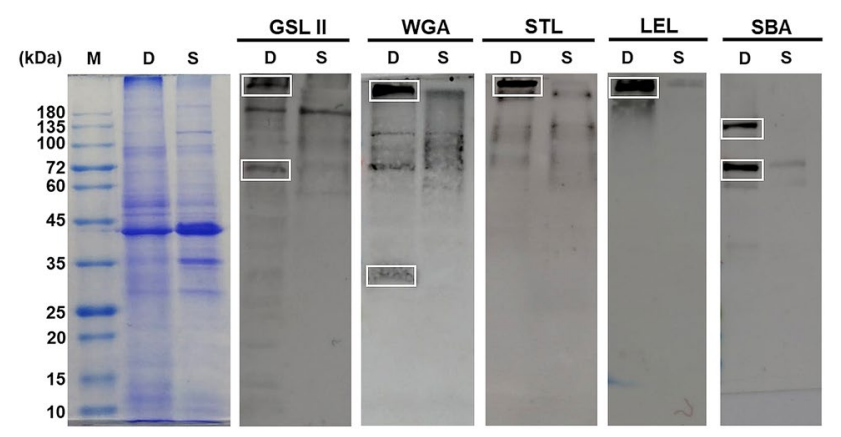

Fig. 6 Glycoproteins detected in Paracentrotus lividus tube feet disc and stem extracts using the 5 most relevant lectins. One-dimensional gel electrophoresis protein profiles and corresponding lectin blots. GSL II was used to detect proteins conjugated with $N$-acetylglucosamine; WGA, STL and LEL to detect chitobiosis and SBA to detect $\mathrm{N}$-acetylgalactosamine. D disc, GSL II Griffonia simplicifolia lectin II, LEL Lycopersicon esculentum lectin, $M$ molecular weight markers, $S$ stem, SBA Soybean agglutinin, STL Solanum tuberosum lectin, $W G A$ wheat germ agglutinin
Fig. 7 Heat map of lectin-based glycan detection in temporary wet adhesives. The rows display the lectins and the columns represent the tested organisms/techniques/type of samples. Very strong labelling is displayed in bright green, strong labelling in green, weak labelling in dark green and no labelling in dark red. The lectins that weren't tested are displayed in black. ConA Concavaline A, DBA Dolichos biflorus agglutinin, DSL Datura stramonium lectin, ECL Erythrina cristagalli lectin, GSL I/II Griffonia simplicifolia lectin I/II, $L B$ lectin blotting, LCA Lens culinaris agglutinin, LEL Lycopersicon esculentum lectin, $L H$ lectin histochemistry, LPD lectin pull down, PHA-E / -L Phaseolus vulgaris erythro / leuco agglutinin, MAL II Maackia amurensis lectin II, PNA Peanut agglutinin, PSA Pisum sativum agglutinin, $R C A$ Ricinus communis agglutinin I, SBA Soybean agglutinin, SJA-SNA Sambucus nigra agglutinin, STL Solanum tuberosum lectin, UEA I Ulex europaeus agglutinin I, $s W G A$ Succinylated wheat germ agglutinin, VVA Vicia villosa agglutinin, WGA Wheat germ agglutinin

duo-gland systems, a secreted 'de-adhesive substance' was predicted to either outcompete the binding between the adhesive layer and the adhesive organ surface (competition model) or enzymatically degrade the binding (enzymatic model) (Lengerer and Ladurner 2018). Recent studies have reinforced the enzymatic model, since not only in sea urchins, but also in sea stars, proteases have been detected in the footprint proteome of A. rubens (Hennebert et al. 2015), providing further evidences of that the de-adhesive secretion most likely contains enzymes that cleave the bond between animal glycocalyx and adhesive material (Lengerer and Ladurner 2018).

\section{Concluding remarks}

We provide the first evidence that a high molecular weight glycoprotein containing $\mathrm{N}$-acetylglucosamine oligomers is involved in sea urchin temporary adhesion. Ongoing work will reveal the identity of the protein moiety taking advantage of the recently obtained $P$. lividus tube foot transcriptome (Pjeta et al. 2020). Further experiments, with sea urchin from several species, geographical distributions and habitats will further disclose if the identified glycan residues represent or not a commonality in sea urchin adhesives. 


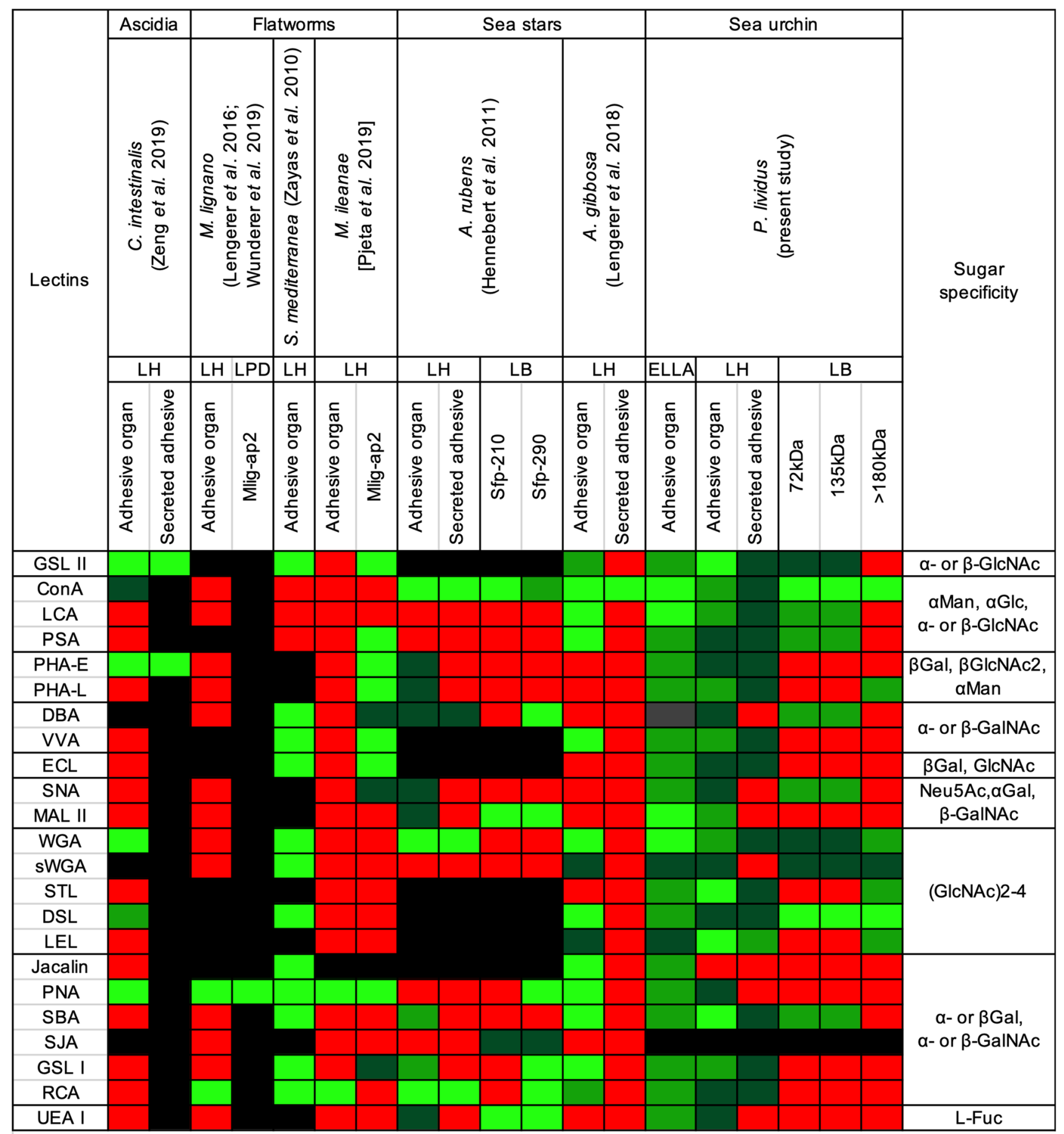

very strong labelling strong labelling no labelling not tested weak labelling 
Acknowledgements Authors would like to thank Maria Byrne, two anonymous reviewers and Sólveig Thorsteinsdóttir for their critical review of this work; FCUL Microscopy Facility, a node of the Portuguese Platform of BioImaging (PPBI-POCI-01-0145-FEDER-022122), for providing access to fluorescence and confocal microscopes; and European Cooperation in Science and Technology (COST) Action CA15216 (European Network of Bioadhesion Expertise) for supporting the participation of RS at COST action meetings to present the results contained in this paper.

Funding This research was funded by Fundação para a Ciência e Tecnologia through a research contract attributed to RS (IF/00006/2015/ CP1276/CT0001) and project grants (UID/Multi/00612/2019, UID/ MAR/04292/2013). To support open access publication this work received funding from the European Union's Horizon 2020 research and innovation program under grant agreement $n^{\circ} 810139$ project PORTWIMS.

\section{Compliance with ethical standards}

Conflict of interests The authors declare no competing interests.

Ethics approval All applicable international, national and/or institutional guidelines for sampling, care, and experimental use of organisms for the study have been followed and all necessary approvals have been obtained.

Open Access This article is licensed under a Creative Commons Attribution 4.0 International License, which permits use, sharing, adaptation, distribution and reproduction in any medium or format, as long as you give appropriate credit to the original author(s) and the source, provide a link to the Creative Commons licence, and indicate if changes were made. The images or other third party material in this article are included in the article's Creative Commons licence, unless indicated otherwise in a credit line to the material. If material is not included in the article's Creative Commons licence and your intended use is not permitted by statutory regulation or exceeds the permitted use, you will need to obtain permission directly from the copyright holder. To view a copy of this licence, visit http://creativecommons.org/licenses/by/4.0/.

\section{References}

Bajanca F, Luz M, Duxson MJ, Thorsteinsdóttir S (2004) Integrins in the mouse myotome: developmental changes and differences between the epaxial and hypaxial lineage. Dev Dynam 231:402-415

Cerra A (1999) Lectin histochemistry of the hyaline layer around the larvae of Patiriella species (Asteroidea) with different developmental modes. J Morphol 242(2):91-99

Edelstein AD, Tsuchida MA, Amodaj N, Pinkard H, Vale RD, Stuurman N (2014) Advanced methods of microscope control using $\mu$ Manager software. J Biol Method 1:e10

Flammang P (1996) Adhesion in echinoderms. In: Jangoux M, Lawrence JM (eds) Echinoderm studies. Balkema, Rotterdam, pp 1-60

Flammang P, Jangoux M (1993) Functional morphology of coronal and peristomeal podia in Sphaerechinus granularis (Echinodermata Echinoida). Zoomorphology 113:47-60

Flammang P, Demeuldre M, Hennebert E, Santos R (2016) Adhesive secretions in echinoderms: a review. In: Smith AM (ed) Biological adhesives. Springer International Publishing, Switzerland, pp 193-222
Hennebert E, Wattiez R, Flammang P (2011) Characterisation of the carbohydrate fraction of the temporary adhesive secreted by the tube feet of the sea star Asterias rubens. Mar Biotechnol 13:484-495

Hennebert E, Wattiez R, Demeuldre M, Ladurner P, Hwang DS, Waite JH, Flammang P (2014) Sea star tenacity mediated by a protein that fragments, then aggregates. PNAS 111:6317-6322

Hennebert E, Leroy B, Wattiez R, Ladurner P (2015) An integrated transcriptomic and proteomic analysis of sea star epidermal secretions identifies proteins involved in defense and adhesion. J Proteomics 128:83-91

Leathem AJC, Atkins J (1983) Lectin binding to paraffin sections. In: Bullock GR, Petrusz P (eds) Techniques in immunocytochemistry (vol II). Academic, London, pp 39-70

Lebesgue N, da Costa G, Ribeiro RM, Ribeiro-Silva C, Martins GG, Matranga V, Scholten A, Cordeiro C, Heck AJ, Santos R (2016) Deciphering the molecular mechanisms underlying sea urchin reversible adhesion: a quantitative proteomics approach. J Proteomics 138:61-71

Lengerer B, Ladurner P (2018) Properties of temporary adhesion systems of marine and freshwater organisms. J Exp Biol. 221:jeb182717

Lengerer B, Bonneel M, Lefevre M, Hennebert E, Leclère P, Gosselin E, Ladurner P, Flammang P (2018) The structural and chemical basis of temporary adhesion in the sea star Asterina gibbosa. Beilstein J Nanotechnol 9:2071-2086

Lengerer B, Algrain M, Lefevre M, Delroisse J, Hennebert E, Flammang P (2019) Interspecies comparison of sea star adhesive proteins. Philos Trans R Soc B Biol Sci 374:20190195

Ohkawa K, Nishida A, Yamamoto H, Waite JH (2004) A glycosylated byssal precursor protein from the green mussel Perna viridis with modified dopa side- chains. Biofouling 20:101-115

Pagett HE, Abrahams JL, Bones J, O’Donoghue N, Marles-Wright J, Lewis RJ, Harris JR, Caldwell GS, Rudd PM, Clare AS (2012) Structural characterisation of the $N$-glycan moiety of the barnacle settlement-inducing protein complex (SIPC). J Exp Biol 215:1192-1198

Pjeta R, Wunderer J, Bertemes P, Hofer T, Salvenmoser W, Lengerer B, Coassin S, Erhart G, Beisel C, Sobral D, Kremser L, Lindner H, Curini-Galletti M, Stelzer C-P, Hess MW, Ladurner P (2019) Temporary adhesion of the proseriate flatworm Minona ileanae. Phil Trans R Soc B 374:20190194

Pjeta R, Lindner H, Kremser L, Salvenmoser W, Sobral D, Ladurner P, Santos R (2020) Integrative transcriptome and proteome analysis of the tube foot and adhesive secretions of the sea urchin Paracentrotus lividus. Int.1 J. Mol, Sci, p 946

Reimer CL, Crawford BJ (1990) Lectin histochemistry of the hyaline layer in the asteroid. Pisaster ochraceus J Morphol 203(3):361-375

Roth Z, Yehezkel G, Khalaila I (2012) Identification and quantification of protein glycosylation. Int J Carbohydr Chem 2012:640923

Rzepecki LM, Waite JH (1993) The byssus of the zebra mussel, Dreissena polymorpha. II. Structure and polymorphism of byssal polyphenolic protein families. Mol Mar Biol Biotechnol 2:267-279

Santos R, Flammang P (2006) Intra- and interspecific variation of the attachment strength in sea urchins. Mar Ecol Prog Ser 332:129-142

Santos R, Gorb S, Jamar V, Flammang P (2005) Adhesion of echinoderm tube feet to rough surfaces. J Exp Biol 208:2555-2567

Santos R, da Costa G, Franco C, Gomes-Alves P, Flammang P, Coelho AV (2009) First insights into the biochemistry of tube foot adhesive from the sea urchin Paracentrotus lividus (Echinoidea, Echinodermata). Mar Biotechnol 11:686-698

Santos R, Barreto A, Franco C, Coelho AV (2013) Mapping sea urchins tube feet proteome - a unique hydraulic mechano-sensory adhesive organ. J Proteomics 79:100-113 
Schindelin J, Arganda-Carreras I, Frise E et al (2012) Fiji: an opensource platform for biological-image analysis. Nat Methods 9:676-682

Smith AM, Morin MC (2002) Biochemical differences between trail mucus and adhesive mucus from marsh periwinkle snails. Biol Bull 203:338-346

Smith AM, Quick TJ, St Peter RLS (1999) Differences in the composition of adhesive and non-adhesive mucus from the limpet Lottia limatula. Biol Bull 196:34-44

Toubarro D, Gouveia A, Ribeiro RM, Simões N, da Costa G, Cordeiro C, Santos R (2016) Cloning, characterization, and expression levels of the Nectin gene from the tube feet of the sea urchin Paracentrotus lividus. Mar Biotechnol 18:372-383

Thompson R, Creavin A, O'Connell M, O'Connor B, Clarke P (2011) Optimization of the enzyme-linked lectin assay for enhanced glycoprotein and glycoconjugate analysis. Anal Bioch 413:114-122

Urushida Y, Nakano M, Matsuda S, Inoue N, Kanai S, Kitamura N, Nishino T, Kamino K (2007) Identification and functional characterization of a novel barnacle cement protein. FEBS 274:4336-4346

Viana AS, Santos R (2018) Nanoscale characterization of the temporary adhesive of the sea urchin Paracentrotus lividus. Beilstein $\mathrm{J}$ Nanotechnol 9:2277-2286

Wunderer J, Lengerer B, Pjeta R, Bertemes P, Kremser L, Lindner H, Ederth T, Hess MW, Stock D, Salvenmoser W, Ladurner P (2019) A mechanism for temporary bioadhesion. PNAS 116:4297-4306

Zhao H, Sagert J, Hwang DS, Waite JH (2009) Glycosylated hydroxytryptophan in a mussel adhesive protein from Perna viridis. J Biol Chem 284:23344-23352

Zeng F, Wunderer J, Salvenmoser W, Ederth T, Rothbächer U (2019) Identifying adhesive components in a model tunicate. Phil Trans R Soc B 374:20190197

Publisher's Note Springer Nature remains neutral with regard to jurisdictional claims in published maps and institutional affiliations. 